\title{
INFLUENCE OF THE COLUMN WEB PANEL BEHAVIOUR ON THE CHARACTERISTICS OF A BEAM-TO-COLUMN JOINT
}

\author{
Alfonsas Daniūnas ${ }^{1}$, Kęstutis Urbonas ${ }^{2}$ \\ Vilnius Gediminas Technical University, Saulètekio al. 11, LT-10223 Vilnius, Lithuania \\ E-mail: ${ }^{2}$ kestutis.urbonas@vgtu.lt (corresponding author) \\ Received 27 Aug. 2012; accepted 28 Jan. 2013
}

\begin{abstract}
The paper reviews the importance of evaluation of actual joint behaviour during the design and manufacture of frame construction. The authors applied the component method, which is used in Eurocode 3. Additionally, they provided a short overview of beam-to-column joint components. The research focuses on one part of the joint-column web panel. It investigates the influence of the column web panel to the rotational stiffness and design moment resistance of the joint. The article presents several possibilities for stiffening the column web panel plate. Calculation results illustrate the influence of the characteristics of column web panel to the rotational stiffness and design moment resistance of the joint. Calculations were carried out both with an unstiffened and with a stiffened column web panel plates. The results confirmed the expected assumptions, i.e. the column web panel is an essential part of the joint, and its behaviour has a significant influence on the rotational stiffness and design moment resistance of the joint. In all calculations where column web panel was stiffened, the rotational stiffness and design moment resistance of the joint increased.
\end{abstract}

Keywords: steel structures, semi-rigid joints, column web panel, component method, initial rotational stiffness, design moment resistance, Eurocode 3.

Reference to this paper should be made as follows: Daniūnas, A.; Urbonas, K. 2013. Influence of the column web panel behaviour on the characteristics of a beam-to-column joint, Journal of Civil Engineering and Management 19(2): 318-324.

\section{Introduction}

In most cases, global analyses of structures are still performed according to the assumption that joints are either ideally rigid or ideally pinned, in spite of the fact that majority of the joints are neither ideally rigid nor ideally pinned (Chen et al. 1996; Hasan et al. 1998; Goto, Miyashita 1998; van Keulen et al. 2003). In most cases, design soft allows applying semi-rigid joints; however, designers have little experience in the field, which limits a wide use of semi-rigid joint concept.

Structural and economic benefit of using the semi-rigid joints is widely known. The real behaviour of the framework allows designing better fitting and safer structures, herewith reaching the economic benefit (Misiūnaitè et al. 2012; Kala 2012; Karkauskas, Popov 2011; Turkalj et al. 2012). Recently, the topic of semi-rigid joints has been increasingly investigated. Many investigations have been performed with different joints of steel frameworks (Faella et al. 2000; Díaz et al. 2011a; Wilkinson, Hancock 2000).

Production of a joint that would behave as rigid or pinned is not simple. More materials (additional stiffeners, bigger bolts, thicker plates and etc.) are required to achieve such joint characteristics Production of such elements not only requires more materials but also more production time. To reduce such expenses, the concept of semi-rigid joints is presented. The idea suggests that joints could be produced as simply and as fast as possible, however, real characteristics of these joints must be evaluated in global analysis. Although more time is required for design, the production and mounting becomes short and simple.

The main characteristics of the joint are initial rotational stiffness and design moment resistance. These characteristics depend on the type of the joint, geometrical data, connection type, used materials and etc. Behaviour of joint impacts on the results of the behaviour (internal forces, deflections) of the whole steel framework (Daniūnas, Urbonas 2010; Díaz et al. 2011b, 2012; Lukoševičienè, Daniūnas 2012).

The so-called component method is widely used to calculate the characteristics of joints. The method is rather fast and simple. It is used in the steel design code Eurocode 3 (2005).

Investigation of web behaviour of column-beam joints mainly focuses on a more accurate evaluation 
of web strength and stiffness. Unfortunately, insufficient attention has been given to parametric study of web stiffness and strength depending on web geometrical data or introducing additional stiffening elements. The aim of this paper is to present results of parametric investigation of web stiffness and strength depending on web transfer or diagonal stiffener geometrical data.

\section{Component method for modelling of joints}

The evaluation of a joint behaviour using the component method consists of three main steps: identification of the component, evaluation of the mechanical properties of the components and assembling components into one mechanical model (Jaspart 2002; Sokol et al. 2002).

Set of actual components depends on the type of a joint (Daniūnas, Urbonas 2008). For beam-tocolumn joint characteristics of the column web panel in shear, transverse compression and transverse tension, column flange and end-plate in bending, bolts in tension and etc. have to be considered. A key aspect is to identify elastically-plastic and rigidly-plastic behaviour of the components (Bahaari, Sherbourne 2000). Elastically-plastic components could be deformed and failed. These components have an influence on the rotational stiffness and moment resistance of the joint. The rigidly-plastic components could have an influence on the design moment resistance of the joint. These components are so stiff that have no influence on the rotational stiffness of the joint. That is the reason only resistance of rigidly-plastic component has to be evaluated.

Force $F_{E d}$ in the components can be found by:

$$
F_{E d}=\frac{M_{E d}}{z} .
$$

Deformation of the component depends on the stiffness coefficient of the component and force in the component (Weynand et al. 1995):

$$
\Delta_{i}=\frac{F_{E d}}{k_{i} \cdot E}
$$

where: $k_{i}$ - component stiffness coefficient; $E$ - the Young modulus; $z$ - the lever arm.

The rotation of the joint can be expressed by formula:

$$
\Phi=\frac{\sum \Delta_{i}}{z} .
$$

Initial rotational stiffness of the joint is ratio of the bending moment and rotation:

$$
S_{j, \text { ini }}=\frac{M_{E d}}{\Phi}=\frac{F_{E d} \cdot z}{\frac{\Sigma \Delta_{i}}{z}}=\frac{E \cdot z^{2}}{\sum \frac{1}{k_{i}}} .
$$

Rotational stiffness of the joint evaluates physical nonlinearity of the components. Value or rotational stiffness can be found by the formula (Eurocode 3 2005):

$$
S_{j}=\frac{E \cdot z^{2}}{\mu \cdot \sum \frac{1}{k_{i}}},
$$

where: $\mu=\left(1.5 M_{j, E d} / M_{j, R d}\right)^{\Psi} ; \Psi$ - coefficient depends on the type of the joint.

The design moment resistance of the joint is equal:

$$
M_{j, R d}=F_{R d} \cdot z,
$$

$F_{R d}=\min \left[F_{R d, i}\right]$, where $\min \left[F_{R d, i}\right]-$ resistance of the weakest component.

According to the values of stiffness and resistance of the components, initial rotational stiffness of the joint $S_{j, \text { ini }}$ and design moment resistance $M_{j, R d}$ could be calculated. Rotational stiffness $S_{j}$ depends on the initial rotational stiffness and magnitude of the bending moment. The initial rotational stiffness $S_{j, \text { ini }}$ may be used in the global analysis only if bending moment does not exceed $2 / 3 \cdot M_{j . R d}$. In this case, it is assumed that physical nonlinearity does not occur (Fig. 1). Independently of the magnitude of a bending moment in all of the cases of global analysis, rotational stiffness $S_{j}$ may be used.

\section{Influence of column web panel characteristics on the behaviour of joint}

Variety of beam-to-column joints is quite wide. Beam to the column could be connected by welds or by bolts, or using angle cleats or end-plates. In some cases, haunched beams can be used as well.

Beam-to-column joint consists of two parts: a column web panel plate and a connection area. In many cases, column web panel has a significant influence on the rotational stiffness and moment resistance of the joint (Hendrick, Murray 1983; Kuhlmann, Kühnemund 2001; Jordão et al. 2004; Brandonisio et al. 2011; da Silva et al. 2012).



Fig. 1. Moment-rotations characteristic of a joint 


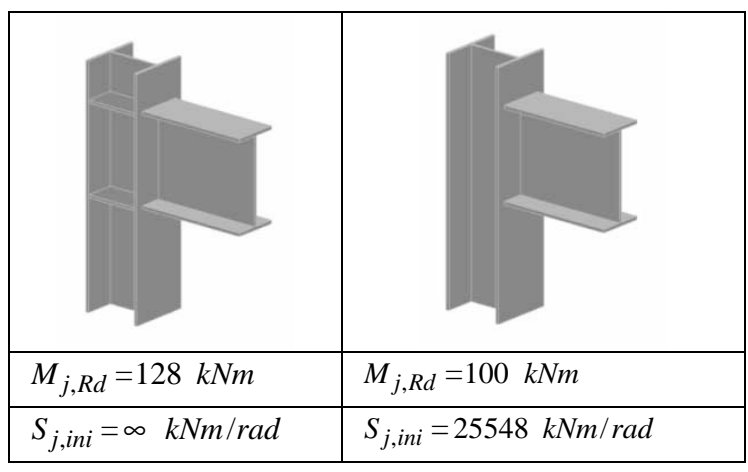

Fig. 2. Welded beam-to-column joint with and without stiffeners

Column web panel is in shear, transverse compression and transverse tension forces (see Eq. 1). Resistances for these forces of the column web have to be evaluated.

The shear resistance of the column web panel directly depends on the shear area of the columns $A_{v c}$ and can be found by formula:

$$
V_{w p, R d}=\frac{0.9 \cdot f_{y, w c} \cdot A_{v c}}{\sqrt{3} \cdot \gamma_{M 0}}
$$

Resistance of column web in transverse compression:

$$
F_{c, w c, R d}=\frac{\omega \cdot k_{w c} \cdot b_{e f f, c, w c} \cdot t_{w c} \cdot f_{y, w c}}{\gamma_{M 0}},
$$

where: $\omega$ - reduction factor; $b_{\text {eff } t, w c}$ - the effective width of column web in compression; $t_{w c}$ - thickness of the column web.

Resistance of column web in transverse tension:

$$
F_{t, w c, R d}=\frac{\omega \cdot b_{e f f, t, w c} \cdot t_{w c} \cdot f_{y, w c}}{\gamma_{M 0}}
$$

where: $b_{\text {eff,t,wc }}$ - the effective width of column web in tension.

Resistances (shear, compression, tension) of the column web, moment resistance and rotational stiffness of the joint could be increased by adding transverse and diagonal stiffeners and supplementary web plates.

If properly stiffened, a column web panel is considered as a rigid component and deformability of it could be disregarded. Deformability of the unstiffened column web panel is significant and it cannot be disregarded. It has to be calculated as provided in this chapter.

Stiffness coefficient of the column web panel in shear $k_{1}$ can be found by formula:

$$
k_{1}=\frac{0.38 \cdot A_{v c}}{\beta \cdot z},
$$

where: $\beta-$ the transformation parameter depending on the configuration of the joint (single-sided or double-sided) and magnitudes and directions of bending moments.

Stiffness coefficient of the column web in compression $k_{2}$ can be found by formula:

$$
k_{2}=\frac{0.7 \cdot b_{e f f, c, w c} \cdot t_{w c}}{d_{c}},
$$

where: $d_{c}$ - clear depth of the column web.

Stiffness coefficient of the column web in tension $k_{3}$ can be found by formula:

$$
k_{3}=\frac{0.7 \cdot b_{e f f, t, w c} \cdot t_{w c}}{d_{c}} .
$$

As already mentioned, a column web panel has an influence on rotational stiffness of a joint and may determine the design moment resistance of the joint. The literature does not offer wide discussions on the extent of the effect a column web panel has on characteristics of a joint. In this article, the parametric analysis is provided to illustrate the influence a of a column web panel on the characteristics of a joint.

\section{Gauge of column web panel parameters on joints stiffness and strength characteristics}

To clarify influence of the characteristics of a column web panel on a joint behaviour, calculations of beamto-column joints were performed. Joints with the same cross-sections and same steel grade were analysed. The only difference is that some joints were stiffened by additional stiffeners while others were not.

The calculations were made for three cases. In all cases, column cross-sections were from profiles HEA220 and beams from IPE330. The steel grade of all members was S355. In all cases, the design moment resistance and initial rotational stiffness results of the joints with and without stiffeners were compared.

Case 1. Beam-to-column joints with welded connections are illustrated in Fig. 2. The presented joints were identical except that one joint was without stiffeners and another one with transverse $10 \mathrm{~mm}$ thick stiffeners.

Performed calculations have shown that the joint with transverse stiffeners is ideally rigid. For calculation of initial rotational stiffness of such type of joints only three components were taken into account. These components were: column web panel in shear, column web in transverse compression and in transverse tension. Due to transverse stiffeners deformations of the column web became insignificant. That is why according to the calculation results, a joint becomes ideally rigid.

In design moment resistance calculations, strength of all of the components has to be calculated. It does not matter whether these components are 


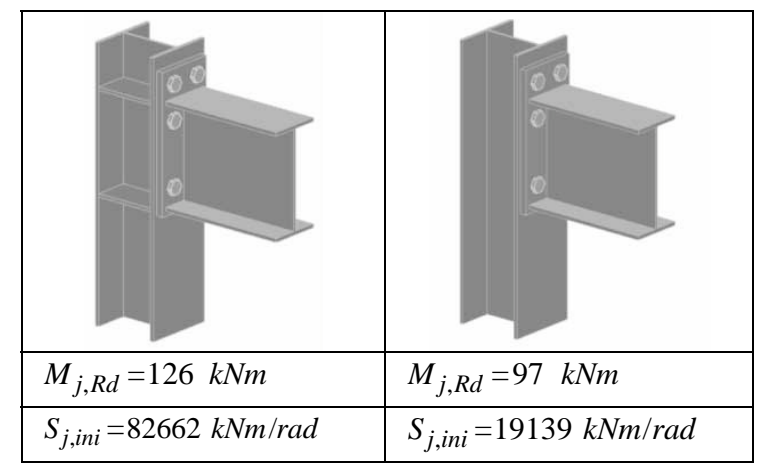

Fig. 3. Bolted beam-to-column joint with extended endplate with and without stiffeners

elastically-plastic or rigidly-plastic. In case of the analysed unstiffened joint, the weakest component as the column web in compression. After the installation of transverse stiffeners, the design moment resistance of the joint increased by $28 \%$ and the column web panel in shear became the weakest component of the joint. Calculation results of design moment resistance and initial rotational stiffness are presented in Fig. 2.

For joints with the transverse stiffeners, installation of additional diagonal $8 \mathrm{~mm}$ thick stiffeners increased only design moment resistance from $128 \mathrm{kNm}$ up to $164 \mathrm{kNm}$. The column web panel in shear remained to be the weakest component of the joint and the joint was perfectly rigid.

In the presented beam-to-column joint with welded connection, added transverse and diagonal stiffeners increased the design moment resistance of the joint up to $64 \%$ and ensured the ideal rigidity of the joint.

Case 2. In this case, joints with extended endplate connection with two bolt-rows in tension (Fig. 3) were analysed. M24 bolts of 8.8 grade and $20 \mathrm{~mm}$ thick end-plate were used for connection. One joint was without stiffeners and another one with transverse $10 \mathrm{~mm}$ thick stiffeners.

In case of this type of joints, calculations have to consider the following components: column web panel in shear, column web in transverse compression and tension, column flange and end-plate in bending, bolts in tension.

Joint views, values of initial rotational stiffness and design moment resistance for joints are presented in Fig. 3. Calculations demonstrated that the transverse stiffeners increased the design moment resistance by almost $30 \%$; and the initial rotational stiffness by as many as $330 \%$. The weakest component of unstiffened joint was the column web in transverse compression, while in case of the joint with transverse stiffeners the column web panel in shear.

Once joints with transverse stiffeners are supplemented with diagonal $8 \mathrm{~mm}$ thick stiffeners, the web panel in shear remains being the weakest component
Table 1. Joint characteristics (when M16, $t_{e p}=10 \mathrm{~mm}$ )

\begin{tabular}{lcc}
\hline & $\begin{array}{c}M_{j, \text { Rd }} \\
(k N m)\end{array}$ & $\begin{array}{c}S_{j, \text { ini }} \\
(k N m / \mathrm{rad})\end{array}$ \\
\hline $\begin{array}{l}\text { Unstiffened joint } \\
\text { Joint with transverse } \\
\text { stiffeners }\end{array}$ & 77 & 15772 \\
\begin{tabular}{l} 
Difference $(\%)$ \\
\hline
\end{tabular} & 80 & 44663 \\
\hline
\end{tabular}

of the joint, but the design moment resistance increases up to $162 \mathrm{kNm}$ and the initial rotational stiffness remains the same as is the case only with transverse stiffeners $-82662 \mathrm{kNm} / \mathrm{rad}$.

In this case, the use of transverse and diagonal stiffeners to strengthen the column web panel plate can increase the design moment resistance by $67 \%$ and the initial rotational stiffness by 3.3 times. Such significant increase in value of the initial rotational stiffness of the joints is possible as other deformable components remain very stiff.

When components of the connection area are less stiff (diameter of bolts reduces to $16 \mathrm{~mm}$ and the end-plate thickness up to $10 \mathrm{~mm}$ ), the stiffened column web panel does not result in a significant increase of the initial rotational stiffness. Results of these calculations are presented in Table 1. The weakest component of the unstiffened joint is the column web in transverse compression, while in case of a joint with transverse stiffeners - the column flange in bending.

Although the addition of transverse stiffeners increases the initial rotational stiffness by approximately three times, it is still insufficient to consider the joint rigid. This result is caused by the flexibility of the connection area. Column web stiffeners do not affect characteristics of the connection area. Therefore, with or without stiffeners, in most real-life cases, joint with such somewhat flexible connection would be perceived as semi-rigid.

Case 3. The Fig. 4 demonstrates joints with a bolted end-plate connection and only one bolt-row in tension. M24 bolts of 8.8 grade and $20 \mathrm{~mm}$ thickness end-plate were used for connection. One joint is

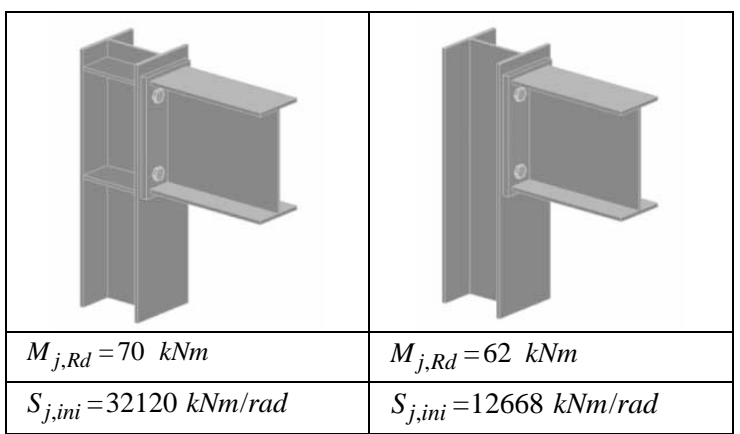

Fig. 4. A bolted beam-to-column joint with and without stiffeners 
Table 2. Joints characteristics (when $\mathrm{M} 16$, tep $=10 \mathrm{~mm}$ )

\begin{tabular}{lcc}
\hline & $\begin{array}{c}M_{j, R d} \\
(k N m)\end{array}$ & $\begin{array}{c}S_{j, \text { ini }} \\
(k N m / \mathrm{rad})\end{array}$ \\
\hline Unstiffened joint & 47 & 10415 \\
Joint with transverse & 47 & 20918 \\
$\quad$ stiffeners & 0 & 50.2 \\
\hline Difference $(\%)$ & 0 & \\
\hline
\end{tabular}

without stiffeners and another - with transverse $10 \mathrm{~mm}$ thick stiffeners.

In calculations of this type of joints, similarly as in Case 2, behaviour of column web panel in shear, column web in transverse compression and tension, column flange and end-plate in bending, bolts in tension have to be taken into account.

Joint views, values of initial rotational stiffness and design moment resistance for joints are presented in Fig. 4. Because of their geometry, these joints with an unextended end-plate and tensile bolt row below the beam flange have to be more flexible and weaker than the joints with an extended end-plate (Case 2). This is demonstrated in the calculation results, which demonstrate that transverse stiffeners increase the design moment resistance by almost $13 \%$ and the initial rotational stiffness by more than $153 \%$. The weakest component of unstiffened joints is the column web in transverse compression, while in case of joints with transverse stiffeners - the column web panel in shear.

Once a joint with transverse stiffeners is supplemented with diagonal $8 \mathrm{~mm}$ thick stiffeners, the design moment resistance increases very little - up to $72 \mathrm{kNm}$ and the initial rotational stiffness remains the same as in case only with transverse stiffeners - $32120 \mathrm{kNm} /$ rad. In this case, the column flange in bending becomes the weakest component of the joint.

Summing up the Case 3, it can be said that the column web plate stiffened by transverse and diagonal stiffeners can increase the design moment resistance by $16 \%$ and the initial rotational stiffness by $153 \%$. In both cases, joints have to be considered as semi-rigid.

Furthermore, calculations of joints were performed when the components in the connection area

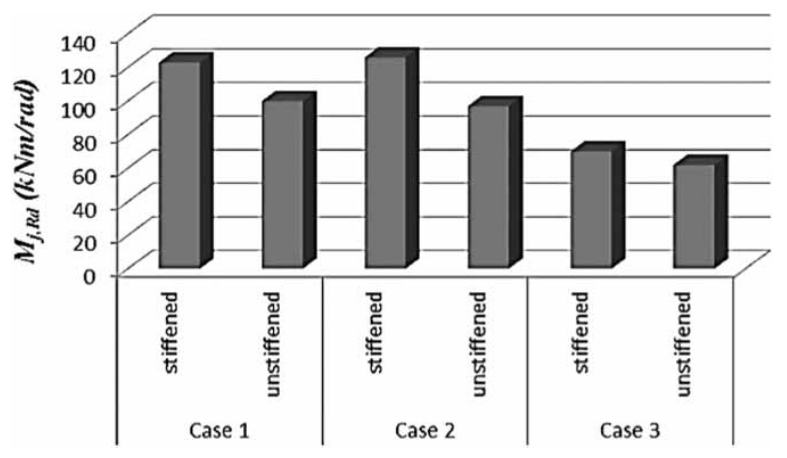

Fig. 5. The moment resistance of the joints were less stiff: bolt diameter was reduced to $16 \mathrm{~mm}$ and the end-plate thickness up to $10 \mathrm{~mm}$.

When the components of the connection area are of reduced stiffness, the weakest component of joints without stiffeners and with transverse stiffeners is the same, i.e. the end-plate in bending. The design moment resistance remains the same, while the initial rotational stiffness difference is about $50 \%$ (Table 2). As determined by the values of initial rotational stiffness, the joints in the global analysis have to be considered as semi-rigid.

Summary of calculations. In the global analysis, the decision regarding the type of joints as rigid, nominally pinned or semi-rigid depends not only on the joint characteristics or cross-sections, but also on the geometry of the analysed framework, from presence/absence and efficiency of bracings. The respective exact limits are presented in Eurocode 3 (2005).

In all three analysed cases, when no stiffeners were added, joints were semi-rigid. In the global analysis, rigidity characteristics of joints have to be evaluated. Idealization to ideally rigid or ideally pined is not allowed.

Results vary depending on the column web panel stiffened by transverse stiffeners. In the Case 1, the joint is perfectly rigid. In the Case 2, whether the joint can be considered as rigid depends on the above presented factors, but in the majority of realistic cases, the joint could be considered as rigid. In the Case 3, the joint is likely always had to be considered as semirigid.

The moment resistance design results are presented graphically in Fig. 5. The results show the difference of design moment resistance of the unstiffened joints and joints with transverse stiffeners.

Fig. 6 shows the initial rotational stiffness results of the joints. In Case 1, the initial rotational stiffness of the stiffened joint is infinite (the ideally rigid joint).

Subsequent to calculations, it may be noted that the transverse column web stiffeners increase the initial rotational stiffness and the design moment resistance of the joints. Additional diagonal stiffeners increase only the design moment resistance, but the

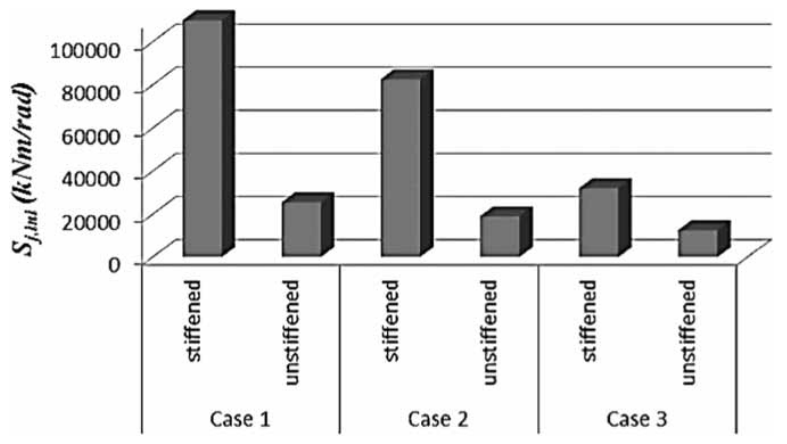

Fig. 6. The initial rotational stiffness of the joints 
initial rotational stiffness remains unchanged. Use of rather flexible components for the connection area (thin end-plates, small bolt and etc.) and additional column web stiffeners does not result in sufficient stiffness of a joint to be assumed as rigid in the global analysis of structures.

\section{Comments and conclusions}

(1) Investigations were carried out by splitting the beam-to-column joints into two constitutive parts: the column web panel and the connection. Calculations were performed when the column web panel was unstiffened, stiffened by transverse stiffeners and by transverse and diagonal stiffeners. Influence of the column web panel was obtained by comparison of the calculation results.

(2) Parametric case of the web stiffening using web stiffeners shows a simple possibility to increase the web and joint stiffness and strength.

(3) Welded beam-to-column joint without stiffeners is semi-rigid. Same joint with column web stiffeners is ideally rigid, because the joint has no components where elastic deformations occur. When the column web panel is stiffened by transverse stiffeners, the design moment resistance of the joint increases by $28 \%$, when transverse and diagonal stiffeners are added $64 \%$.

(4) If the weakest component of the joint is the column web panel in shear, compression or tension, the design resistance of these components can be increased using stiffeners. Then, the design moment resistance of the joint increases as well. In performed calculations, the transverse stiffeners increased design moment resistance by 28,30 and $13 \%$, while the use of transverse and diagonal stiffeners together increased the design moment resistance by 64,67 and $16 \%$, respectively, in all cases.

(5) When components of connection area are sufficiently rigid (Case 2), the use of column web stiffeners can achieve a rigid beam-tocolumn joint. In this case, the use of transverse stiffeners increased the initial torsional stiffness by more than three times. In the Case 3 , when the connection components are relatively rigid, the use of stiffeners increased the initial rotational stiffness by 1.5 times, however, due to its geometry; the joint was not sufficiently stiff to satisfy the requirements for a rigid joint. In addition, the transverse and diagonal stiffeners for joints in Cases 2 and 3, the initial rotational stiffness no longer increases.
(6) In the analysed cases with bolted connections, when the components of connection area are less stiff, the use of stiffeners can increase the initial rotational stiffness of the joint by approximately $2-3$ times, but the joint remains insufficiently rigid to be considered as rigid.

\section{References}

Bahaari, M. R.; Sherbourne, A. N. 2000. Behavior of eightbolt capacity endplate connections, Computers \& Structures 77(3): 315-325. http://dx.doi.org/10.1016/S0045-7949(99)00218-7.

Brandonisio, G.; De Luca, A.; Mele, E. 2011. Shear instability of panel zone in beam-to-column connections, Journal of Constructional Steel Research 67(5): 891-903. http://dx.doi.org/10.1016/j.jcsr.2010.11.019

Chen, W. F.; Goto, Y.; Liew, J. Y. R. 1996. Stability design of semi-rigid frames. USA. John Wiley \& Sons. 488 p.

Daniūnas, A.; Urbonas, K. 2008. Analysis of the steel frames with the semi-rigid beam-to-beam and beamto-column knee joints under bending and axial forces, Engineering Structures 30(11): 3114-3118. http://dx.doi.org/10.1016/j.engstruct.2008.04.027

Daniūnas, A.; Urbonas, K. 2010. Influence of the semi-rigid bolted steel joints on the frame behaviour, Journal of Civil Engineering and Management 16(2): 237-241. http://dx.doi.org/10.3846/jcem.2010.27

da Silva, L. S.; Jordão, S.; Simões, R. 2012. A component model for welded beam-to-column joints with beams of unequal depth, Stahlbau 81(4): 290-303. http://dx.doi.org/10.1002/stab.201201544

Díaz, C.; Marti, P.; Victoria, M.; Querin, O. M. 2011 a. Review on the modelling of joint behaviour in steel frames, Journal of Constructional Steel Research 67(5): 741-758. http://dx.doi.org/10.1016/j.jcsr.2010.12.014

Díaz, C.; Victoria, M.; Martí, P.; Querin, O. M. 2011b. FE model of beam-to-column extended end-plate joints, Journal of Constructional Steel Research 67(10): 15781590. http://dx.doi.org/10.1016/j.jcsr.2011.04.002

Díaz, C.; Victoria, M.; Querin, O. M.; Martí, P. 2012. Optimum design of semi-rigid connections using metamodels, Journal of Constructional Steel Research 78: 97-106. http://dx.doi.org/10.1016/j.jcsr.2012.06.013

Eurocode 3 Design of Steel Structures. Part 1-8: Design of Joints. CEN, European Committee for Standardization, Brussels, 2005. 133 p.

Faella, C.; Piluso, V.; Rizzano, G. 2000. Structural steel semirigid connections: theory, design and software. Boca Raton: CRC Press LLC. 536 p.

Goto, Y.; Miyashita, S. 1998. Classification system for rigid and semirigid connections, Journal of Structural Engineering ASCE 124(7): 750-757. http://dx.doi.org/10.1061/(ASCE)0733-9445(1998) 124:7(750)

Hasan, R.; Kishi, N.; Chen, W.-F. 1998. A new nonlinear connections classification system, Journal of Constructional Steel Research 47(1-2): 119-140. http://dx.doi.org/10.1016/S0143-974X(98)80105-3 
Hendrick, A.; Murray, T. M. 1983. Column web and flange strength at end-plate connections. Report No. FSEL/ AISC 83-01, Fears Structural Engineering Laboratory, University of Oklahoma, Norman, Okla.

Jaspart, J.-P. 2002. Design of structural joints in building frames, Progress in Structural Engineering and Materials 4(1): 18-34. http://dx.doi.org/10.1002/pse.105

Jordão, S.; da Silva, L. S.; Simões, R. 2004. Numerical evaluation of the response of the column web panel under asymmetrical patch loading, in Proc. of the Seventh International Conference on Computational Structures Technology, Civil-Comp Press, Stirlingshire, UK, Paper 154, 2004. http://dx.doi.org/10.4203/ccp.79.154

Kala, Z. 2012. Geometrically non-linear finite element reliability analysis of steel plane frames with initial imperfections, Journal of Civil Engineering and Management 18(1): 81-90. http://dx.doi.org/10.3846/13923730.2012.655306

Karkauskas, R.; Popov, M. 2011. The analysis of geometrically nonlinear elastic-plastic space frames, Journal of Civil Engineering and Management 17(4): 558-568. http://dx.doi.org/10.3846/13923730.2011.602983

Kuhlmann, U.; Kühnemund, F. 2001. Proposal of a new design resistance of the joint component column web in compression. Report 2001-7x. Institut für Konstruktion und Entwurf Universität Stuttgart, Germany.

Lukoševičienè, O.; Daniūnas, A. 2012. Safety design of steel beams with time-dependent stability, Archives of Civil and Mechanical Engineering 13: 112-118.
Misiūnaitė, I.; Daniūnas, A.; Juozapaitis, A. 2012. Unconventional double-level structural system for underdeck cable-stayed bridges, Journal of Civil Engineering and Management 18(3): 436-443. http://dx.doi.org/10.3846/13923730.2012.700106

Sokol, Z.; Wald, F.; Delabre, V.; Muzeau, J. P.; Švarc, M. 2002. Design of end plate joints subject to moment and normal force, Eurosteel Coimbra 2002: 1219-1228.

Turkalj, G.; Brnic, J.; Lanc, D.; Kravanja, S. 2012. Updated lagrangian formulation for nonlinear stability analysis of thin-walled frames with semi-rigid connections, International Journal of Structural Stability and Dynamics 12(3): 1250013-1-1250013-23.

van Keulen, D. C.; Nethercot, D. A.; Snijder, H. H.; Bakker, M. C. M. 2003. Frame analysis incorporating semirigid joint action: applicability of the half initial Secant stiffness approach, Journal of Constructional Steel Research 59(9): 1083-1100. http://dx.doi.org/10.1016/S0143-974X(03)00031-2

Weynand, K.; Jaspart, J. P.; Steenhuis, M. 1995. The stiffness model of revised Annex $\mathrm{J}$ of Eurocode 3, in Proc. of the Third International Workshop on Connections in Steel Structures, 29-31 May, 1995, Trento, Italy, 441-452.

Wilkinson, T.; Hancock, G. J. 2000. Tests to examine plastic behaviour of knee joints in cold-formed RHS, Journal of Structural Engineering ASCE 126(3): 297-305. http://dx.doi.org/10.1061/(ASCE)0733-9445(2000)126: $3(297)$

\footnotetext{
Alfonsas DANIŪNAS. Doctor, Professor in the Department of Steel and Timber Structures, Vilnius Gediminas Technical University, Lithuania. He is an author and co-author of more than 150 articles on science and organisation of higher education. Research interests: analysis and optimization of elastic and plastic steel structures, numerical methods, semi-rigid joints of steel structures.
}

Kestutis URBONAS. Doctor, Assoc. Professor of the Department of Steel and Timber Structures of Vilnius Gediminas Technical University. Research interests: calculations of steel structures, semi-rigid steel joints, thinwalled steel structures. 